\title{
Not easy: a son reflects on assisted dying
}

\author{
Cite as: CMAJ 2018 July 16;190:E859-60. doi: 10.1503/cmaj.180173 \\ CMAJ Podcasts: article reading at https://soundcloud.com/cmajpodcasts/180173-enc
}

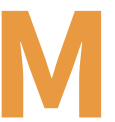

y family had numerous arguments around the dinner table about end-of-life care. Our parents had made their wishes clear: no extraordinary efforts, no resuscitation and, preferably, the "pill" when they wished to depart. We, the offspring, all agreed - none of us wanted to be alive and not sentient as well.

We explored the obligations of the relatives, doctors and the objections from the "right to lifers." We also discussed instances where the process had been corrupted by the acquiescence of doctors to ruling authorities such as the Nazis and Russians. Indeed, our father had witnessed children from a mental institution shuffle two-by-two down cobbled streets draped with Nazi flags to their fates, until his grandmother, in shame, had pulled him from the window.

But end of life is not black and white; it is a descent into a shifting fog of grayness. The slow decline of physical ability as our father's heart weakened, the increasing sleep and daytime naps, the loss of hygienic care, the catheter bag leaking into the old matrimonial bed, and the astounding capacity of our mother to accept and continue caring for him. There were flashes of the "old man," the engagement with the outside world through a question as to whether I had read the latest Economist, but then he reverted to a child talking about the hallucinations from the latest hospital admission, and how the visiting nurses came at the wrong time and disturbed him.

The crisis came as a response to cleanliness; he became both incoherent and incontinent, a huge challenge to his past pride, which had vanished with catheter bags and blister packs. Our mother could no longer cope. A solution emerged as my sister took the long drive

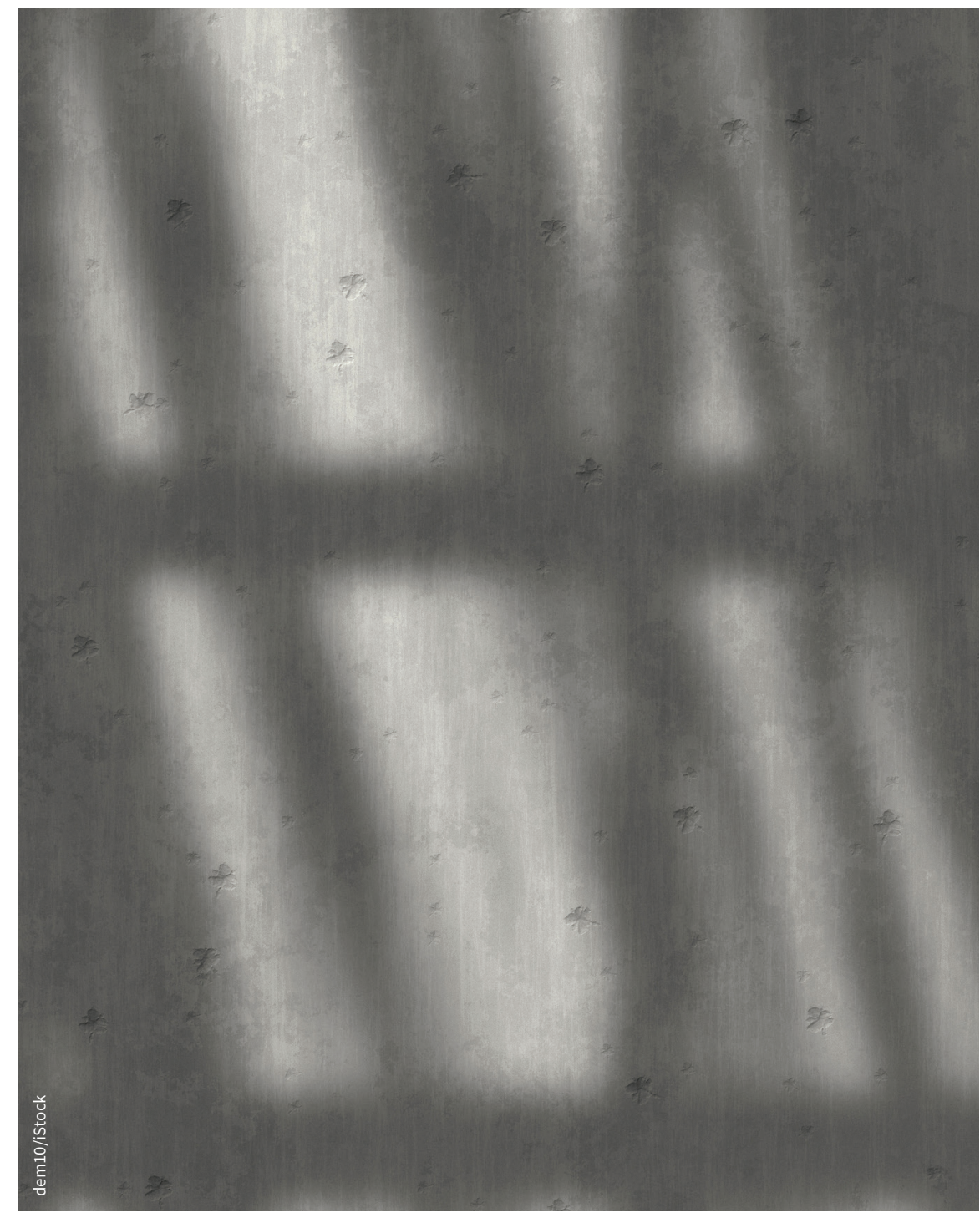

back "home" to address the situation. On a Monday morning, three emotionally overwhelmed children delivered our father to the centre for respite care. He had a relatively quick death once his medications were discontinued but not a true assisted death.

If we had followed our father's wishes (made very clearly 20 years ago), a doctor would have been called and the pill administered. Indeed, as the medic in the family I had felt the pressure to provide the solution when the time came. But I was drowning in a sea of emotional memories, incapable and unwilling to provide direction from half a world away. Did we have the right to expect someone to come and administer the end to this man, 
surrounded as he was by distraught but pragmatic relatives who recognized that end of life had arrived?

The boundary between a natural and an expedited death is infinitely wide, and muddied by a multitude of expressed and repressed emotions. The slow and often agonizing wait for the laboured breathing to cease allows the release and transfer of those emotions into the mourning and honouring of him. But the longer the wait for such a release, the more the burden, in particular, on the family caregivers.

For those like my father whose essential human drive from a 93-year-old body
I did, as a houseman and newly qualified doctor, deliver end-of-life care to patients with cancer in my training days on the ancient wards of northern England. The pragmatic people living up there rejected prolonged dying. They thought their Uncle Jack or Dad deserved a better and quicker exit with the so-called Brompton cocktail. This solution was both ethical and easy to do in those days, and the respect and thanks were genuine. Is it any easier now?

Laws will protect us and make us better doctors only when we are able to immerse ourselves and survive in the sea

\section{The boundary between a natural and expedited death is infinitely wide ...}

survived the loss of self-knowledge and awareness, there is no easy way out; they have lost the ability to control. During his time, my father had firmly expressed that he did not want to be warehoused in a nursing home when his end arrived. Because of his dementia, he was unable to make any decisions and unable to call upon his relatives to make his wishes clear. But is the diagnosis of dementia alone enough to justify a call for assisted death? At what point in the slow decline into dementia should relatives act on those expressed wishes for an assisted death? of conflicting emotions around dying. I believe that mourning and reflection is a deep part of our emotional development as thinking beings and should be respected. At the same time, a prolongation of life without self-awareness is an imposition when it was stated as such by a person when their mind was clear. Therefore, part of assisted dying must be historical; a clear trail of discussions, documentation and family agreements should be available to the doctor who administers the procedure, to allow a death that is geared to the wishes of that person.
As a son, I wanted an assisted death for my father; as a doctor, I had felt the weight of knowing and expecting that my father's life would likely be called early based on his medical and family history. He died at 93, living much longer than expected thanks to modern medical interventions

Giving a clear history of both of my parents' wishes and our family's resolution to an end-of-life doctor would have eased the potential weight for us and the providing doctor. In my father's case, death came early, but what if it had not? In our age of data collection and preservation, keeping video records should be encouraged so that we can clearly lay out our wishes and free our surviving relatives of any such burdens relating to implementing those wishes. Paper documents, no matter how legal, are not enough; we need to see the whole person to get the best understanding of their wishes.

Perhaps this suggestion can be transmitted to the many people who will ask for medically assisted deaths in the future because, at present, advance directives for this are not legal yet.

My job, as a doctor or a son, was to support the wishes of my father.

\section{Mike Gross MD}

Department of Surgery, Dalhousie

University, Halifax, NS

This article has been peer reviewed.

This is a true story. The family has given their consent for this story to be told. 